\title{
ATRIBUTOS DE SOLO E CULTURA ESPACIALMENTE DISTRIBUÍDOS RELACIONADOS AO RENDIMENTO DO MILHO(1)
}

\author{
Francisco Nogara Neto ${ }^{(2)}$, Glaucio Roloff $^{(3)}$, Jeferson Dieckow ${ }^{(4)} \&$ \\ Antonio Carlos Vargas Motta ${ }^{(4)}$
}

\begin{abstract}
RESUMO
A agricultura de precisão pode aumentar a eficiência e a sustentabilidade da agricultura brasileira de grãos, principalmente auxiliando no manejo do solo e das culturas. $\mathrm{O}$ objetivo deste estudo foi avaliar a importância de atributos de solo e da cultura com variação espacial do rendimento de grãos de milho e o uso dessa informação para aprimorar as decisões sobre o manejo da cultura. Foram utilizados dados da safra 2005/6 de uma gleba comercial de milho de 18 ha, na região de Guarapuava, Paraná, em um solo Latossolo Bruno de textura argilosa. Atributos de solo (0-0,10 m) e cultura foram coletados em quadrículas georreferenciadas com densidade amostral de $2 \mathrm{ha}^{-1}$. $\mathrm{O}$ rendimento de grãos espacializado foi avaliado com sensor de produtividade na colhedora. Esse rendimento apresentou variabilidade espacial (média de $12,4 \mathrm{Mg} \mathrm{ha}^{-1}$, com amplitude entre 11,1 e 14,0 $\mathrm{Mg} \mathrm{ha}^{-1}$ ) relacionada aos atributos do solo: $\mathrm{P}-\mathrm{Mehlich}-1, \mathrm{Mg}^{2+}$, soma de bases e relações Ca:Mg, Mg:K e Mg:CTC, mas não da cultura, conforme uma matriz de correlação de Spearman. A análise por árvore de regressão identificou a saturação por Mg (Mg:CTC), com valor crítico de 0,10, e a relação $\mathrm{Mg}: \mathrm{K}$, com valor crítico de 2,30 , como atributos de solo com efeito mais significativo, pois valores inferiores ao crítico estão relacionados aos menores rendimentos de grão. A análise de cluster confirmou os resultados obtidos com as duas análises estatísticas anteriores, e sua interpretação conjunta suporta a conclusão de que os elementos $\mathbf{P}$ e Mg eram os mais críticos em termos de necessidade de manejo localizado. Comparativamente, o manejo localizado com agricultura de precisão demandaria, na gleba, maior
\end{abstract}

(1) Parte da dissertação de mestrado do primeiro autor apresentada ao Programa de Pós-Graduação em Ciência do Solo, Universidade Federal do Paraná - UFPR. Recebido para publicação em julho de 2010 e aprovado em março de 2011.

(2) Engenheiro-Agrônomo, Mestre em Ciência do Solo. Rua Guairá 2086, CEP 85010-010 Guarapuava (PR). E-mail: f.nogara@uol.com.br

(3) Professor Associado, Departamento de Solos e Engenharia Agrícola, Universidade Federal do Paraná - UFPR. Curitiba (PR). Endereço atual: Universidade Federal da Integração Latino-Americana (UNILA), Parque Tecnológico Itaipu, Foz do Iguaçu, PR. E-mail: groloff@ufpr.br

(4) Professor Adjunto, Departamento de Solos e Engenharia Agrícola, Universidade Federal do Paraná - UFPR. Rua dos Funcionários 1540, CEP 80035-050 Curitiba (PR). Bolsista PQ CNPq. E-mails: jefersondieckow@ufpr.br; mottaacv@ufpr.br 
consumo de calcário (incremento de $6,6 \mathrm{Mg}$, sendo $3,4 \mathrm{Mg}$ de calcário calcítico e $3,2 \mathrm{Mg}$ do tipo dolomítico), menor consumo de $\mathrm{P}_{2} \mathrm{O}_{5}(-235 \mathrm{~kg})$ e maior consumo de $\mathrm{K}_{2} \mathrm{O}$ (+ $\left.135 \mathrm{~kg}\right)$ em relação ao manejo uniforme (tradicional). Contudo, o manejo localizado permite que esses insumos sejam aplicados nas dosagens adequadas em partes específicas da gleba, e não uniformemente em toda a gleba, alterando positivamente a produtividade dessas partes. Quando as tomadas de decisão sobre o manejo são auxiliadas por ferramentas estatísticas apropriadas, a agricultura de precisão é viável tecnicamente para o manejo de atributos químicos do solo, proporcionando assim a otimização no uso de insumos e, potencialmente, contribuindo para o rendimento economicamente ideal.

Termos de indexação: amostragem em malha, correlação de Spearman, árvore de regressão, magnésio, fósforo, manejo localizado.

\title{
SUMMARY: SPATIALLY VARIED SOIL AND CROP ATTRIBUTES RELATED TO CORN YIELD
}

\begin{abstract}
Precision agriculture can increase efficiency and sustainability of grain crops in Brazil, especially in support of soil and crop management. In this study the importance of spatiallyvariable soil and crop attributes on the variability of grain crop yield and the use of this information to improve management decisions was examined. The study used data from the 2005 / 6 corn growing season of a 18 ha commercial field on a clayey Latossolo Bruno (FAO: Ferralsol). Soil (0-0.10 m layer) and crop properties were sampled at a density of two per ha. Spatially distributed crop yield was determined with a grain sensor on the harvester. Yield variability (average of $12.4 \mathrm{Mg} \mathrm{ha}^{-1}$, amplitude between 11.1 and $14.0 \mathrm{Mg} \mathrm{ha}^{-1}$ ) was related to the soil properties - P Mehlich, $\mathrm{Mg}^{2+}$, sum of bases and Ca:Mg, Mg:K and Mg:CEC ratios - but not with crop attributes, according to the results of a Spearman correlation matrix. Regression analysis identified a critical value of Magnesium saturation (Mg:CEC) of 0.10, and a critical $\mathrm{Mg}: K$ ratio of 2.3, as the most significant soil properties. Below the critical values, yields were reduced. Cluster analysis confirmed the results obtained by the two previous statistical techniques, and their combined interpretation supported the conclusion that Pand Mg were the two nutrients for which spatial management is most needed. Compared to the traditional fixed-rate, whole-field application, using variable rate application would require, for the whole field, $6.6 \mathrm{Mg}$ of additional lime, being $3.4 \mathrm{Mg}$ calcitic lime and $3.2 \mathrm{Mg}$ dolomitic lime, less $\mathrm{P}_{2} \mathrm{O}_{5}$ $(-235 \mathrm{~kg})$, and more $\mathrm{K}_{2} \mathrm{O}(+135 \mathrm{~kg})$ than in the normal uniform management. However, with variable rates such inputs would be applied at adequate rates to specific parts of the field, positively affecting the yields in these parts. When management decisions are supported by appropriate statistical tools, precision agriculture is technically viable for the management of soil chemical properties, allowing for optimized dosages, with a view to an ideal economical yield.
\end{abstract}

Index terms: grid soil sampling, Spearman correlation, magnesium, phosphorus, micromanagement.

\section{INTRODUÇÃO}

A agricultura de precisão é um sistema de manejo no qual algumas práticas agrícolas são realizadas de forma localizada, de acordo com a variabilidade espacial das características de solo e cultura na gleba, visando à otimização de ganhos econômicos e ambientais que suportem a sustentabilidade do agroecossistema (Pierce \& Nowak, 1999). As perspectivas da agricultura de precisão são promissoras em termos de automação de práticas visando à aplicação de insumos em taxas variáveis. Apesar disso, as formas de identificação dos fatores de produção espacialmente dominantes e limitantes em cada sistema específico e os critérios para a tomada de decisões sobre quais fatores manejar ainda necessitam ser melhorados (Corá et al., 2004; Molin, 2004; Roloff et al., 2006; Amado et al., 2009; RosaFilho et al., 2009).

Dentre os vários atributos de solo em glebas agrícolas, destaca-se a variabilidade daqueles relacionados à acidez (Silva et al., 2003; Amado et al., 2009; Hurtado et al., 2009), do teor de P (Silva et al., 2003; Corá et al., 2004; Amado et al., 2009) e dos atributos físicos relacionados com compactação (Amado et al., 2009; Rosa-Filho et al., 2009). A 
existência de variabilidade espacial para esses atributos de solo, sobretudo aqueles relacionados à fertilidade e acidez, são evidências de que o manejo uniforme da adubação ou calagem, com doses de fertilizantes e corretivos baseadas em valores médios dos atributos, pode não ser a forma mais racional técnica e economicamente de utilização de insumos em uma gleba agrícola (Corá et al., 2004; Amado et al., 2009). Por exemplo, Hurtado et al. (2009) constataram que, enquanto no manejo localizado, com agricultura de precisão, as doses de calcário em um Latossolo Vermelho, cultivado com milho, variavam nas faixas de $0-0,5$ e $1,5-2,0 \mathrm{Mg} \mathrm{ha}^{-1}$, o manejo uniforme preconizava, simplesmente, a aplicação de uma dose média e uniforme de $0,58 \mathrm{Mg} \mathrm{ha}^{-1}$.

A análise conjunta de dados de produtividade e de variáveis de solo, de cultura, ambientais, biológicas e outras é dificultada pela dependência espacial desuniforme entre esses dados, bem como pela sua distribuição não normal (Schiebelbein, 2006). Isso dificulta a realização de uma análise clara das relações de causa e efeito entre os fatores e a tomada de decisões apropriadas no que diz respeito às praticas de manejo. Contrapondo essa situação e visando ao entendimento das relações mais importantes que interferem na produtividade de um cultivo, Roloff et al. (2006) sugerem o emprego de métodos estatísticos não paramétricos, que não pressupõem distribuição normal nem relações lineares. Essas estatísticas são intuitivas e mais adequadas para as situações em que o usuário da agricultura de precisão se defronta na busca das relações da produtividade com atributos do solo e da cultura passíveis de manejo, objetivando a maior eficiência na produção das lavouras. Dentre essas estatísticas, destacam-se: (i) a correlação de Spearman, uma versão alternativa à usual correlação de Pearson, utilizada na situação de não possuir distribuição normal; (ii) a árvore de regressão, demonstrando quais variáveis independentes têm maior importância na relação com a variável dependente, subdividindo sucessivamente o conjunto de dados em dois subgrupos descendentes; e (iii) análise de cluster, com a finalidade de formar grupos de dados com homogeneidade interna e heterogeneidade externa.

A agricultura de precisão pode ser empregada em qualquer cultivo agrícola, porém apresenta grande potencial de uso e retorno na cultura do milho, por ser esta a que tradicionalmente emprega grau maior de tecnologia em relação a outras culturas de grãos, especialmente na região Sul do Brasil. O Paraná é o maior produtor nacional de milho e, neste Estado, a região de Guarapuava é um importante polo de produção da cultura (Paraná, 2009). O alto potencial produtivo de milho na região deve-se, em parte, às características climáticas decorrentes da altitude superior a $1.000 \mathrm{~m}$, como temperaturas noturnas mais baixas, que possibilitam reduções no metabolismo fisiológico da planta durante a noite e, consequentemente, maior acúmulo de fotossintatos
(Fancelli \& Dourado Neto, 2000). Apesar de já expressivo, entende-se que o potencial produtivo de milho na região pode ser ainda maior com a adoção de tecnologias avançadas, como a agricultura de precisão.

O objetivo deste trabalho foi avaliar, com fundamentação estatística, a importância e interferência de atributos de solo e cultura na variabilidade espacial do rendimento de grãos de milho e a possibilidade de emprego da agricultura de precisão no manejo prático desses atributos em uma gleba comercial de milho, na região de Guarapuava, Paraná.

\section{MATERIAL E MÉTODOS}

\section{Caracterização e mapeamento da área de estudo}

O trabalho foi realizado em uma gleba de 18 ha de cultivo comercial de grãos, situada na Colônia Entre Rios, município de Guarapuava (PR), nas coordenadas geográficas de $25^{\circ} 31^{\prime} \mathrm{S}$ e $51^{\circ} 31^{\prime} \mathrm{W}$ e em uma altitude média de $1.061 \mathrm{~m}$. O estudo foi conduzido na safra de milho 2005/06. O clima local é subtropical, classificado como $\mathrm{Cfb}$, de acordo com a classificação de Köppen, sem estação seca definida e com geadas frequentes e severas durante o inverno (Caviglione et al., 2000). A precipitação pluvial média anual está entre 1.800 e $2.000 \mathrm{~mm}$; a temperatura média do mês mais frio (julho), entre 12 e $13{ }^{\circ} \mathrm{C}$; e a temperatura média do mês mais quente (janeiro), entre 20 e $21^{\circ} \mathrm{C}$ (Caviglione et al., 2000). A precipitação pluvial no período entre a semeadura (última semana de setembro de 2005) e a colheita do milho (última semana de março de 2006) foi de $899 \mathrm{~mm}$, um valor $6 \%$ abaixo da precipitação normal para o período em questão (dados obtidos junto ao Instituto Tecnológico SIMEPAR, Paraná). O solo da gleba é classificado como Latossolo Bruno (Embrapa, 1999), derivado de basalto e com textura muito argilosa ( $>600 \mathrm{~g} \mathrm{~kg}^{-1}$ de argila) na camada de $0-0,20 \mathrm{~m}$. A gleba foi convertida a partir de um ecossistema nativo de campo subtropical para lavoura comercial de grãos no ano de 1957, e desde 1989 vem sendo manejada no sistema plantio direto com rotação de culturas envolvendo espécies como milho e soja, no verão, trigo, cevada e aveia-preta (cobertura), no inverno, sendo esta a cultura que antecedeu a safra estudada. Nenhum trabalho anterior envolvendo agricultura de precisão ou aplicação de insumos à taxa variável foi executado nessa gleba.

O híbrido de milho Pioneer 30F53 foi semeado na última semana de setembro de 2005 , com espaçamento de $0,75 \mathrm{~m}$ entre linhas e população de aproximadamente 80 mil plantas por hectare. A adubação de base constou de $32 \mathrm{~kg} \mathrm{ha}^{-1}$ de N, $120 \mathrm{~kg} \mathrm{ha}^{-1}$ de $\mathrm{P}_{2} \mathrm{O}_{5}$ e $80 \mathrm{~kg} \mathrm{ha}^{-1}$ de $\mathrm{K}_{2} \mathrm{O}$, seguida pela aplicação de $\mathrm{N}$ em 
cobertura (196 kg ha-1 de N) na forma de ureia. As três últimas calagens foram feitas em 1999, $2002 \mathrm{e}$ 2005, com calcário calcítico, em doses de aproximadamente 2,0 a 2,5 $\mathrm{Mg} \mathrm{ha}^{-1}$ (PRNT de aproximadamente 70 \%) aplicadas na superfície e sem incorporação.

O perímetro da gleba foi georreferenciado, por caminhamento, com um computador portátil de mão acoplado a uma antena de GPS com sistema bluetooth. A informação obtida foi simultaneamente processada pelo programa SST FieldRover II versão 10.6 (SST Development Group, Inc.), com a geração do respectivo polígono da área. Uma malha equidistante de 40 pontos espaçados de 70,7 x 70,7 m e representando quadrículas de 0,5 ha (Roloff \& Focht, 2001) foi estabelecida para a gleba, usando o mesmo sistema para georreferenciamento mencionado anteriormente. Cada ponto da malha foi marcado com um piquete devidamente identificado, para permitir o retorno exato ao ponto de amostragem, independentemente dos erros do receptor de GPS.

\section{Avaliação dos atributos de cultura e rendi- mento de grãos de milho}

As informações sobre altura de planta, ataque de lagarta-do-cartucho (Spodoptera frugiperda Smith 1797) e índice de clorofila na folha foram obtidas com a cultura do milho nos estádios fenológicos V10 a V12 (10 a 12 folhas expandidas e com o colar visível), na primeira quinzena de dezembro de 2005. Para cada um dos 40 pontos da malha, foram avaliadas 10 plantas de milho, localizadas nos vértices de um pentagrama de aproximadamente $10 \mathrm{~m}$ de raio em torno do ponto. Quanto à altura de plantas, tomou-se a medida entre a superfície do solo e o ápice do "cartucho". Na avaliação do ataque de lagarta-docartucho, considerou-se cada planta "com" ou "sem" ataque e, a partir da informação das 10 plantas de cada ponto, calculou-se a percentagem de ataque. $\mathrm{O}$ índice de clorofila foi obtido automaticamente por meio de um clorofilômetro, avaliando-se a folha superior que apresentasse o colar visível (Argenta et al., 2001), com uma leitura por folha.

As avaliações de população de plantas, acamamento e quebramento de colmos, espigas com grãos ardidos e número de grãos por espiga foram feitas com a cultura no estádio de grão farináceo, na primeira quinzena de março de 2006, nos mesmos pontos da malha levantados anteriormente. A população de plantas foi avaliada em uma extensão de $5 \mathrm{~m}$ na linha que passava pelo ponto de malha, e de mais quatro linhas adjacentes (duas de cada lado), também de $5 \mathrm{~m}$. $\mathrm{O}$ acamamento e quebramento de colmos foram avaliados nessas mesmas linhas, calculando-se a percentagem de colmos acamados ou quebrados em relação ao número total de plantas. A percentagem de espigas com grãos ardidos foi determinada em 10 espigas da linha central da amostragem de população de plantas. O número de grãos por espiga foi avaliado em cinco espigas abertas, para avaliação de grãos ardidos.
O rendimento de grãos foi avaliado durante a colheita, no dia 29/03/2006, por meio de um sistema com sensor de produtividade e de georreferenciamento de dados (Fieldstar, AGCO Corporation) instalado de fábrica na colhedora. Verificações e calibrações do sensor de produtividade foram realizadas previamente, de acordo com as indicações do fabricante, comparandose a informação de peso de grãos gerada pelo sistema de monitoramento da colhedora com a informação de peso obtida em balança comercial. Os dados de produtividade foram armazenados em um cartão de memória, lidos em um leitor apropriado, que gerou os arquivos de formato "shp" e "dbf", possibilitando a espacialização da produtividade. Os dados de produtividade foram filtrados para eliminar distorções de dados, como valores negativos, dados de produtividade abaixo de 2,0 $\mathrm{Mg} \mathrm{ha}^{-1}$ e acima de $20,0 \mathrm{Mg} \mathrm{ha}^{-1}$. Com a utilização do programa SSTollbox versão 3.5 (SST Development Group, Inc.), foi calculada a média de produtividade no entorno de cada um dos pontos da malha, ou seja, toda a informação de produtividade obtida dentro de um raio de $35 \mathrm{~m}$ em torno do ponto foi resumida em um valor médio, eliminando assim variações de curta distância nos dados de produtividade e possibilitando a obtenção de um valor mais robusto de produtividade para cada ponto (Schiebelbein et al., 2006).

\section{Avaliação dos atributos de solo}

Amostras de solo foram coletadas após a colheita do milho, na primeira quinzena de julho de 2006, quando a gleba estava com cultivo de trigo, em estádio inicial de perfilhamento. Dez subamostras de solo foram coletadas em torno de cada ponto da malha, no mesmo esquema do pentagrama utilizado para as avaliações de planta, com o auxílio de um trado calador, posicionando-se o ponto de coleta em local correspondente à entrelinha da cultura anterior de milho (ainda era possível identificar as linhas de milho). A amostragem foi feita para a camada de 0 $0,10 \mathrm{~m}$, seguindo as orientações da Comissão de Química e Fertilidade do Solo do RS e SC para o sistema plantio direto consolidado (CQFSRS/SC, 2004).

As análises de solo foram realizadas com base nos métodos descritos por Pavan et al. (1992), determinando-se os seguintes atributos: $\mathrm{pH}-\mathrm{CaCl}_{2}, \mathrm{pH}$ SMP, $\mathrm{Al}^{3+}, \mathrm{H}+\mathrm{Al}$, P Mehlich- $1, \mathrm{~K}^{+}, \mathrm{Ca}^{2+}, \mathrm{Mg}^{2+}$, soma de bases (SB), CTC, saturação por bases (V), saturação por $\mathrm{Al}(\mathrm{m})$ e teor de argila. Foram também calculadas as relações entre bases (Ca:Mg, Ca:K e $\mathrm{Mg}: \mathrm{K})$ e a saturação da CTC com Ca (Ca:CTC), com Mg (Mg:CTC) e com K (K:CTC).

\section{Análises estatísticas}

Os dados foram submetidos ao teste de aderência de Kolmogorov-Smirnov ( $\alpha=5 \%$ ), verificando-se que a maioria das variáveis não apresentava distribuição normal - algo relativamente comum em estudos dessa natureza (Corá et al., 2004; Schiebelbein, 2006; Amado et al., 2009). Em razão disso, todas as variáveis foram 
analisadas por meio da matriz de correlação não paramétrica de Spearman, utilizando-se o programa estatístico Systat versão 9.0 (Systat Software Inc.). Considerou-se como variável dependente deste estudo o rendimento de grãos. Pelo fato de a matriz de correlação de Spearman ser de caráter exploratório, as variáveis independentes que apresentavam correlação (r) com rendimento de grãos igual ou superior a 0,40 (valor arbitrário) foram submetidas a duas análises complementares (Roloff et al., 2006): análise por árvore de regressão; e análise de cluster, empregando-se variáveis normalizadas, por meio do mesmo programa estatístico: Systat versão 9.0. A árvore de regressão demonstra, em um diagrama, quais variáveis independentes têm maior importância no resultado da variável dependente, subdividindo sucessivamente o conjunto de dados em dois subgrupos descendentes. A análise de cluster tem a finalidade de agrupar os dados segundo suas características, formando grupos com homogeneidade interna e heterogeneidade externa.

\section{RESULTADOS E DISCUSSÃO}

Atributos de solo e cultura responsáveis pela variabilidade no rendimento de grãos

O rendimento médio de grãos de milho na área foi de $12,35 \mathrm{Mg} \mathrm{ha}^{-1}$ (Quadro 1), caracterizando uma situação de alto rendimento em comparação às médias de 4,66 e 3,30 $\mathrm{Mg}_{\text {ha }}{ }^{-1}$ obtidas no Paraná (Paraná, 2009) e no Brasil (CONAB, 2009), respectivamente, para a safra 2005/06. Apesar do elevado rendimento médio, este não foi uniforme na gleba e variou em $3,0 \mathrm{Mg} \mathrm{ha}^{-1}$, entre o menor $\left(11,06 \mathrm{Mg} \mathrm{ha}^{-1}\right)$ e o maior valor observado (14,04 $\left.\mathrm{Mg} \mathrm{ha}^{-1}\right)$ para as médias no entorno dos pontos de amostragem (Quadro 1). Isso evidencia a existência de variabilidade espacial para o rendimento de grãos na área (Figura 1) e justifica, portanto, a aplicação de estratégias de manejo localizado preconizadas pela agricultura de precisão.

Confirmada a variabilidade espacial para o rendimento de grãos, o passo seguinte foi identificar os principais atributos de solo e cultura associados funcionalmente a essa variabilidade. O rendimento de grãos apresentou correlação de Spearman superior a 0,40 somente com atributos de solo: P-Mehlich $(\rho=0,47), \mathrm{Mg}^{2+}(\rho=0,60), \mathrm{SB}(\rho=0,48)$, relação Ca:Mg $(\rho=-0,56)$, relação Mg:K $(\rho=0,52)$ e Mg:CTC ( $\rho=0,55)$ (Quadro 2). A comparação visual entre a representação espacial de rendimento de grãos (Figura 1) e a dos atributos mencionados (Figura 2) também confirma, de forma aproximada, essas relações. Esses atributos de solo são, portanto, os principais determinadores da variabilidade no rendimento de grãos e, por isso, passam a ser considerados como prioritários dentro de um plano de

Quadro 1. Mínima, máxima, média, desvio-padrão e coeficiente de variação (CV) dos valores obtidos para rendimento de grãos de milho (valores médios no entorno dos pontos de amostragem), atributos de solo $(0-0,10 \mathrm{~m})$ e atributos de cultura

\begin{tabular}{|c|c|c|c|c|c|}
\hline Atributo & Mínima & Máxima & Média & Desvio-padrão & CV (\%) \\
\hline Rendimento grãos ( $\left.\mathrm{Mg} \mathrm{ha}^{-1}\right)$ & 11,06 & 14,04 & 12,35 & 0,80 & 6,4 \\
\hline $\mathrm{pH}-\mathrm{CaCl}_{2}$ & 4,9 & 6,1 & 5,5 & 0,3 & 6,0 \\
\hline $\mathrm{pH}-\mathrm{SMP}$ & 5,4 & 6,6 & 6,2 & 0,3 & 4,7 \\
\hline $\mathrm{Al}^{3+}\left(\mathrm{cmol}_{\mathrm{c}} \mathrm{dm}^{-3}\right)$ & 0,00 & 0,20 & 0,01 & 0,05 & 370,7 \\
\hline $\mathrm{H}+\mathrm{Al}\left(\mathrm{cmol}_{\mathrm{c}} \mathrm{dm}^{-3}\right)$ & 3,20 & 7,80 & 4,46 & 1,06 & 23,9 \\
\hline P-Mehlich $\left(\mathrm{mg} \mathrm{dm}^{-3}\right)$ & 5,7 & 25,1 & 11,1 & 4,4 & 39,9 \\
\hline $\mathrm{K}^{+}\left(\mathrm{mg} \mathrm{dm}^{-3}\right)$ & 78 & 261 & 168 & 44 & 25,9 \\
\hline $\mathrm{Ca}^{2+}\left(\mathrm{cmol}_{\mathrm{c}} \mathrm{dm}^{-3}\right)$ & 3,00 & 5,50 & 3,91 & 0,55 & 14,2 \\
\hline $\mathrm{Mg}^{2+}\left(\mathrm{cmol}_{\mathrm{c}} \mathrm{dm}^{-3}\right)$ & 0,50 & 1,70 & 1,00 & 0,34 & 34,5 \\
\hline $\mathrm{SB}\left(\mathrm{cmol}_{\mathrm{c}} \mathrm{dm}^{-3}\right)$ & 3,53 & 7,73 & 5,36 & 0,90 & 16,8 \\
\hline $\mathrm{CTC}\left(\mathrm{cmol}_{\mathrm{c}} \mathrm{dm}^{-3}\right)$ & 8,47 & 13,89 & 9,83 & 1,23 & 12,5 \\
\hline $\mathrm{V}(\%)$ & 40,0 & 68,0 & 54,9 & 7,4 & 13,6 \\
\hline $\mathrm{m}(\%)$ & 0,0 & 3,0 & 0,2 & 0,7 & 361,6 \\
\hline $\mathrm{Ca}: \mathrm{Mg}$ & 2,5 & 6,7 & 4,3 & 1,2 & 27,3 \\
\hline $\mathrm{Ca}: \mathrm{K}$ & 4,9 & 20,0 & 9,1 & 2,8 & 31,3 \\
\hline $\mathrm{Mg}: \mathrm{K}$ & 1,2 & 4,8 & 2,2 & 0,8 & 34,3 \\
\hline $\mathrm{Ca}: \mathrm{CTC}$ & 0,29 & 0,49 & 0,40 & 0,05 & 12,5 \\
\hline Mg:CTC & 0,06 & 0,17 & 0,10 & 0,03 & 30,0 \\
\hline $\mathrm{K}: \mathrm{CTC}$ & 0,02 & 0,08 & 0,05 & 0,01 & 30,2 \\
\hline Argila $\left(\mathrm{g} \mathrm{kg}^{-1}\right)$ & 538 & 800 & 718 & 52 & 7,2 \\
\hline População de plantas (mil plantas ha ${ }^{-1}$ ) & 68,6 & 88,1 & 79,8 & 5,1 & 6,4 \\
\hline Espigas com grãos ardidos (\%) & 0 & 60 & 11 & 14 & 126,6 \\
\hline Número de grãos por espiga & 437 & 770 & 601 & 83 & 13,8 \\
\hline Acamamento e quebramento de colmos (\%) & 0,0 & 3,0 & 0,4 & 0,7 & 189,2 \\
\hline Índice de clorofila & 49,60 & 58,77 & 55,32 & 2,24 & 4,1 \\
\hline Ataque de lagarta-do-cartucho (\%) & 10 & 60 & 27 & 13 & 50,2 \\
\hline Altura de plantas $(\mathrm{cm})$ & 94 & 139 & 118 & 10 & 8,3 \\
\hline
\end{tabular}




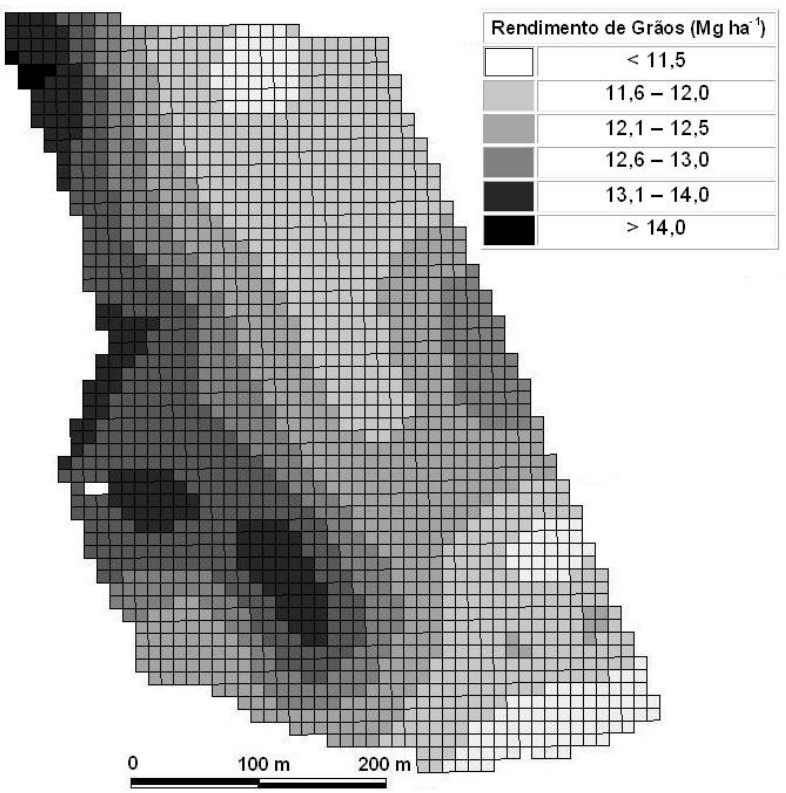

Figura 1. Espacialização do rendimento de grãos de milho.

manejo localizado, em agricultura de precisão. Apesar de serem seis atributos, eles se resumem basicamente em dois elementos nutrientes considerados críticos em termos de manejo da variabilidade na gleba: $\mathrm{P}$ e $\mathrm{Mg}$, sendo o último o responsável pelas variações na SB e nas relações entre bases. Nenhum dos atributos de cultura mostrou correlação de Spearman superior a 0,40 com o rendimento de grãos (Quadro 1), não sendo, portanto, considerados como críticos nas condições do estudo.

Identificados os principais atributos responsáveis pela variabilidade no rendimento de grão, entre aqueles quantificados, avaliou-se a importância destes por meio da técnica estatística de árvore de regressão (Figura 3). O primeiro atributo de solo a subdividir o conjunto total de dados obtidos nos 40 pontos de avaliação de rendimento foi a saturação por $\mathrm{Mg}$ (Mg:CTC), com valor crítico de 0,10, abaixo do qual ficou um subgrupo de menor rendimento (média de 11,9 $\mathrm{Mg} \mathrm{ha}^{-1}$ ) e, acima, um grupo de maior rendimento (média de 12,91 $\mathrm{Mg} \mathrm{ha}^{-1}$ ) (Figura 3). O segundo atributo da árvore de regressão foi a relação $\mathrm{Mg}: \mathrm{K}$, que, no valor de 2,30, dividiu o subgrupo de maior rendimento do nível anterior em dois subsubgrupos. A partir dessas informações da árvore de regressão, ficou evidente que o Mg é o que requer mais atenção em termos de manejo da variabilidade espacial do rendimento dessa gleba e que as estratégias práticas devem ser voltadas no sentido de aumentar a saturação $\mathrm{Mg}$ :CTC e a relação $\mathrm{Mg}: \mathrm{K}$ para acima dos valores críticos identificados de 0,10 e 2,30, respectivamente. Como a principal fonte de $\mathrm{Mg}$ disponível na região é o calcário, manejar esse elemento significa manejar a calagem, principalmente no que se refere à escolha do tipo de calcário (calcítico ou dolomítico) (Hurtado et al., 2009).

Por meio da análise de cluster, em complemento às duas análises estatísticas prévias, foram criados três grupos homogêneos para os seis atributos principais de solo mais rendimento de grãos (Figura 4). O grupo "a" (Figura 4a) foi aquele com os níveis mais baixos de rendimento de grãos e também o que apresentou os menores níveis de $\mathrm{Mg}^{2+}, \mathrm{Mg}$ :CTC, SB, PMehlich e Mg:K, e os maiores níveis para a relação Ca:Mg. Os grupos "b" e "c" (Figura 4b,c) representaram os maiores níveis de rendimento de grãos e também os maiores níveis de $\mathrm{Mg}^{2+}, \mathrm{Mg}$ :CTC, SB, PMehlich (exceto no grupo "b") e $\mathrm{Mg}: \mathrm{K}$, e os menores níveis para a relação $\mathrm{Ca}: \mathrm{Mg}$. Os resultados foram coerentes com aqueles da correlação de Spearman e árvore de regressão no sentido de evidenciar as relações diretas entre o rendimento de grãos e os elementos $\mathrm{P}$ e Mg, especialmente este último.

Embora somente algumas variáveis de solo tenham sido consideradas críticas em termos de manejo da variabilidade espacial de rendimento, isso não significa que as demais variáveis não requeiram atenção. Ou seja, elas necessitam ser levadas em consideração, embora seu manejo em campo não necessite, nesse momento, ser localizado, comparativamente àquelas consideradas críticas para a variabilidade do rendimento de grãos, provavelmente por estarem em teores ideais para a gleba.

\section{Relações entre bases}

As relações entre bases Ca:Mg e $\mathrm{Mg}: \mathrm{K}$ apresentaram correlações de Spearman superiores a 0,40 e foram consideradas variáveis críticas na determinação da variabilidade do rendimento de grãos de milho (Quadro 1). No caso da relação Ca:Mg, o elemento-chave que determinou essa relação foi a variação de $\mathrm{Mg}$, com pouca influência do elemento cálcio (Figura 5a,b). Da mesma forma ocorreu para a relação $\mathrm{Mg}: \mathrm{K}$, em que novamente o elemento $\mathrm{Mg}$ foi mais determinante (Figura 5c), em relação ao elemento K (Figura 5d). Isso reforça a constatação de que o rendimento de grãos tem variação direta com o teor de Mg no solo da gleba.

A resposta do rendimento de grãos ao elemento $\mathrm{Mg}$ e às relações $\mathrm{Ca}: \mathrm{Mg}$ e $\mathrm{Mg}: \mathrm{K}$ está, possivelmente, relacionada com o histórico de calagem da área, feita somente com calcário calcítico nas três últimas aplicações (1999, 2002 e 2005), reduzindo assim a aplicação de $\mathrm{Mg}$. A interação entre cátions (Ca, $\mathrm{Mg}$ e K) é citada como importante fator de interferência na produtividade e nutrição de plantas (Büll, 1993; Marschener, 1997). Segundo esses autores, há inibição competitiva desses nutrientes pelo mesmo sítio do carregador para absorção, porém ela poderá ser resolvida se aumentada a concentração do elemento limitante. Trabalhando com milho em casa de vegetação Hernandez \& Silveira (1998) concluíram que a produção de matéria seca foi maior nas situações 


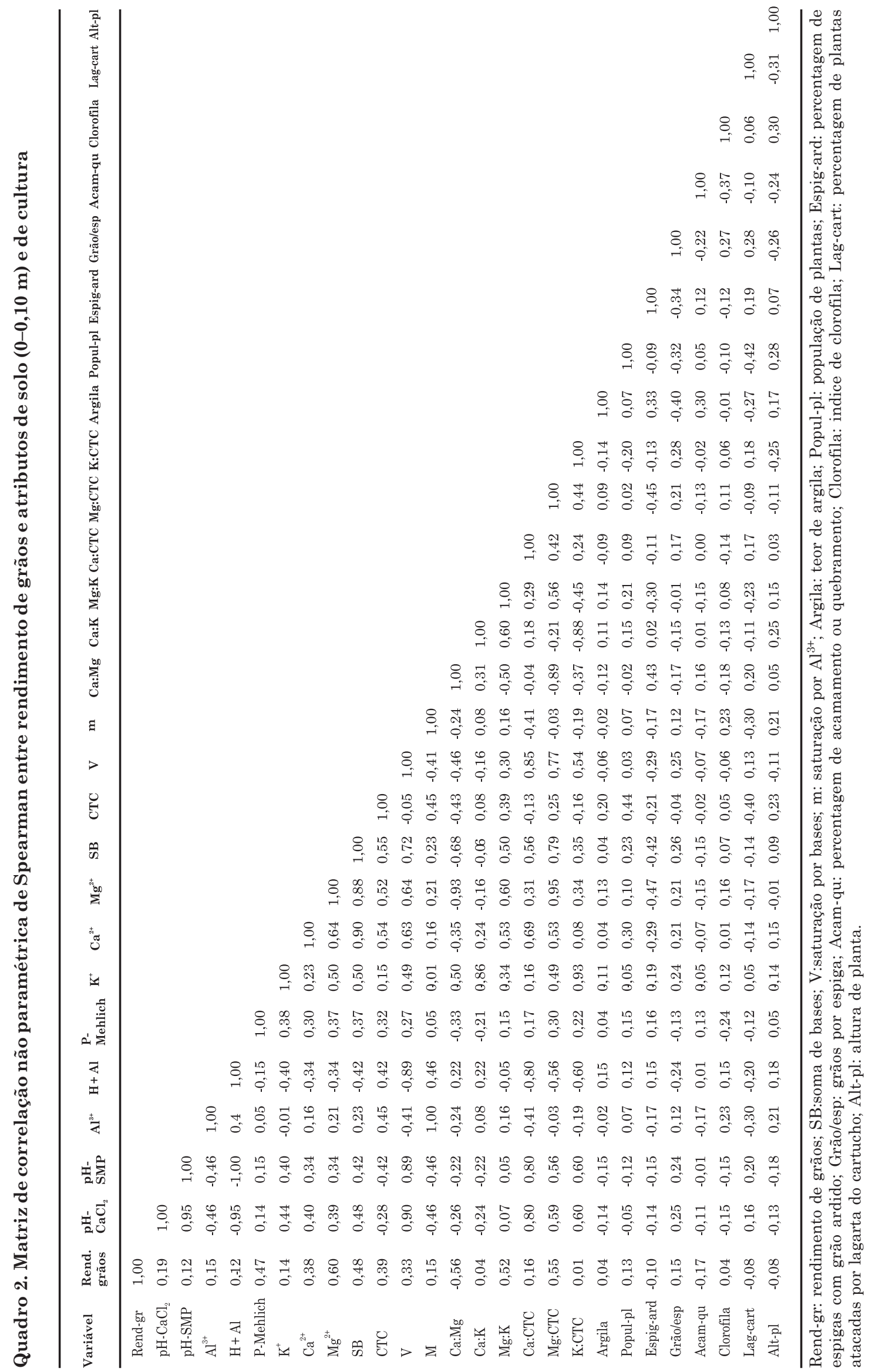



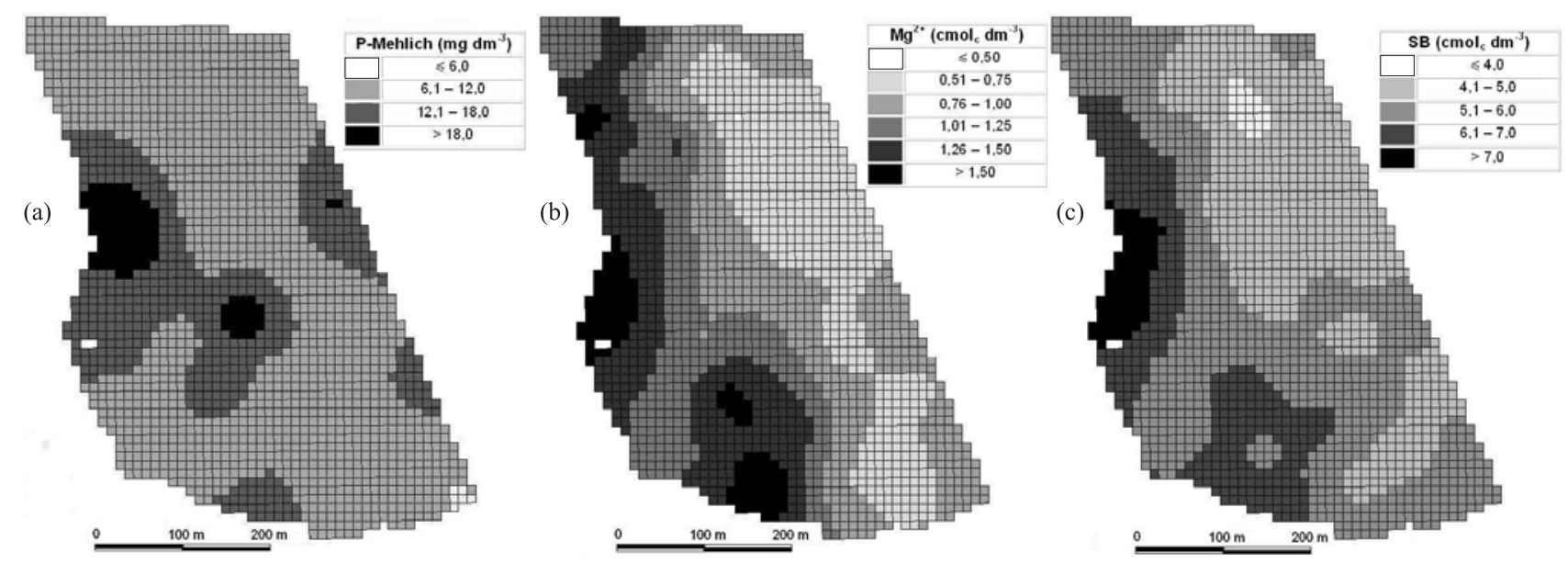

(d)

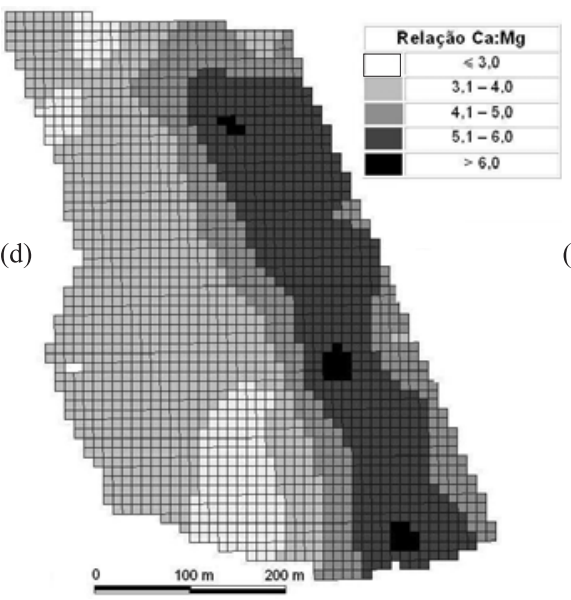

(e)

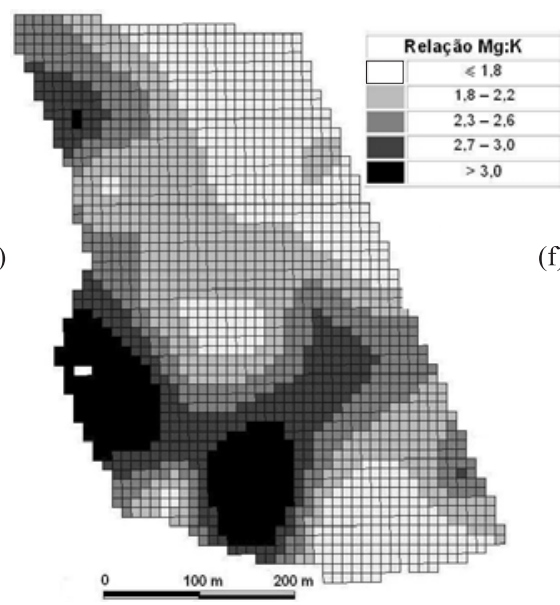

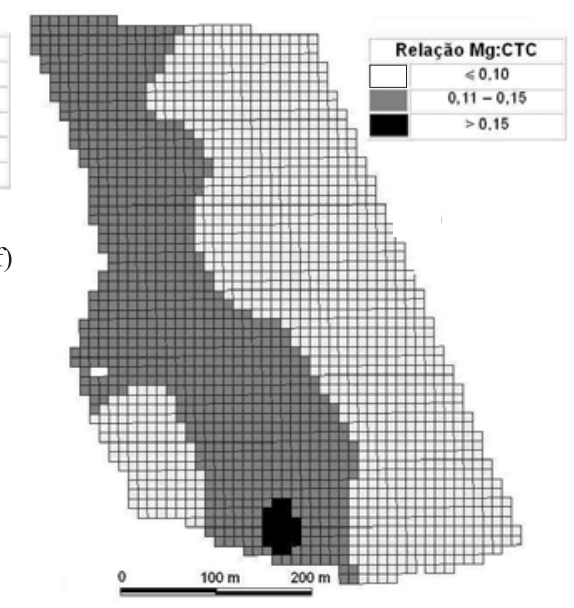

Figura 2. Espacialização dos atributos de solo que apresentaram correlação de Spearman superior a 0,40 (conforme Quadro 2). (a) P-Mehlich; (b) $\mathrm{Mg}^{2+}$; (c) SB = soma de bases; (d) relação Ca:Mg; (e) relação Mg:K; (f) relação Mg:CTC.

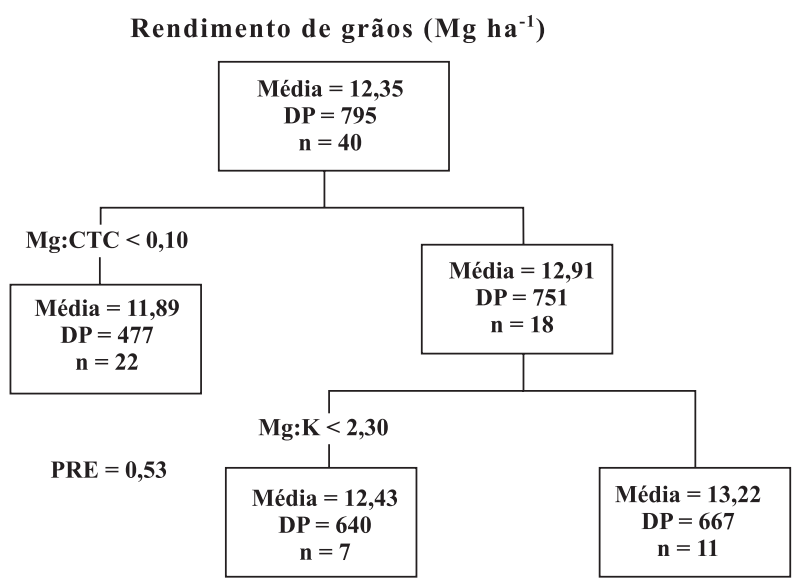

Figura 3. Árvore de regressão das variáveis independentes que apresentaram correlação de Spearman com rendimento de grãos igual ou superior a 0,40 (conforme Quadro 2). Rendimento de grãos $\left(\mathrm{Mg} \mathrm{ha}^{-1}\right)$; $\mathrm{DP}$ - desvio-padrão $\left(\mathrm{Mg} \mathrm{ha}^{-1}\right)$; $\mathrm{n}$ - número de pontos; PRE - redução proporcional de erro.
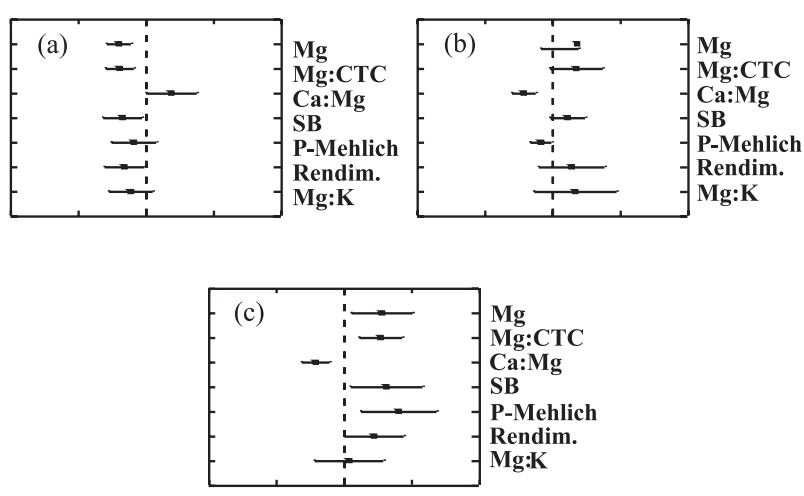

Figura 4. Análise de cluster e os grupos homogêneos $(a, b, c)$ gerados pela proximidade euclidiana entre os valores padronizados dos atributos selecionados (correlação de Spearman com rendimento de grãos igual ou superior a 0,40 ), por meio do método K-means. A linha tracejada indica a média dos atributos, e as linhas horizontais, sua amplitude. Rendim. = rendimento de grãos. 
(a)

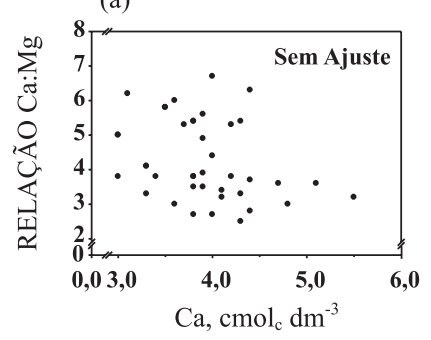

(c)

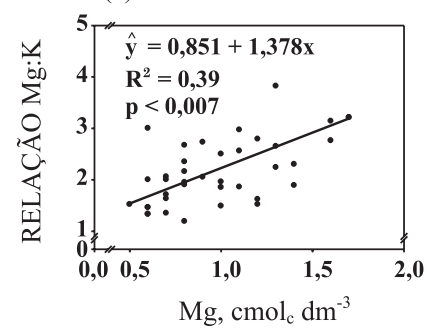

(b)

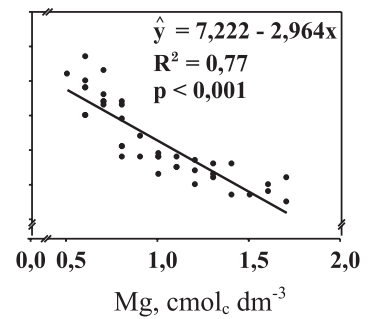

(d)

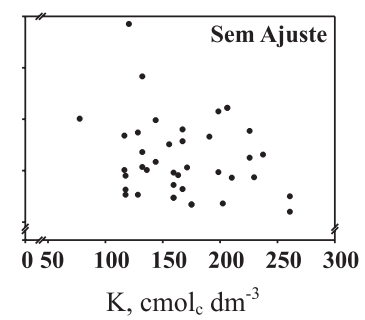

Figura 5. Cátions determinantes das variações nas relações entre bases: (a) Ca versus $\mathrm{Ca}: \mathrm{Mg}$; (b) Mg versus Ca:Mg; (c) Mg versus $\mathrm{Mg}: \mathrm{K}$; (d) $\mathrm{K}$ versus Mg:K.

em que a relação Ca:Mg era inferior a 4:1, sobretudo quando a saturação por bases era de $50 \%$. Apesar da controvérsia sobre o tema envolvendo a percentagem de saturação por bases $\mathrm{Ca}, \mathrm{Mg}$ e K na CTC e a relação entre essas bases, existem evidências de que uma saturação por Mg próxima de 10 \% e uma relação $\mathrm{Mg}: \mathrm{K}$ de 2:1 sejam as mais adequadas para a planta (Kopittke \& Menzies, 2007). A Comissão de Química e Fertilidade do Solo do RS e SC considera, por sua vez, que a relação Ca:Mg passa a ser importante quando um dos elementos estiver em nível baixo (CQFSRS/SC, 2004).

\section{Ferramental estatístico}

Em um plano de agricultura de precisão, uma das etapas mais críticas diz respeito à tomada de decisão sobre quais variáveis de solo e cultura necessitam ser manejadas no sentido de otimizar o rendimento. Nisso reside a necessidade de criação e desenvolvimento de técnicas e métodos estatísticos mais práticos e confiáveis para a identificação dos atributos causadores de variabilidade no campo e, então, de partir para a recomendação do manejo adequado para o cultivo propriamente dito (Buchleiter \& Brodahl, 2000).

A proposta de análise estatística apresentada, que inclui a correlação de Spearman, árvore de regressão e análise de cluster, mostrou-se apropriada para identificar e avaliar a importância dos principais atributos, no caso somente de solo, responsáveis pela variabilidade espacial no rendimento de grãos de milho. Pela correlação de Spearman, constatou-se que os elementos $\mathrm{P}$ e $\mathrm{Mg}$ eram os mais críticos como causa da variabilidade no rendimento e, portanto, de

necessidade de manejo localizado. Entretanto, por meio da análise por árvore de regressão, o Mg mostrou importância relativa maior, expressa pelas relações Mg:CTC e Mg:K (Figura 3). Segundo Buchleiter \& Brodahl (2000), o método de árvores de regressão é um método exploratório de análise estatística que possui maior flexibilidade e não leva em conta muitos dos princípios restritivos considerados pela estatística tradicional. O uso das árvores de regressão pode ser um caminho mais robusto para a pesquisa em campo das relações entre o solo e seus atributos em planos de agricultura de precisão (Roloff et al., 2006).

A análise de cluster, aplicada às seis variáveis selecionadas por meio da correlação de Spearman, serviu para reforçar a existência de relação delas com o rendimento de grãos e aumentar ainda mais o grau de confiança da decisão, tomada no sentido de manejar $\mathrm{P}$ e $\mathrm{Mg}$.

\section{Planos de recomendação de adubação e calagem}

Segundo a Comissão de Química e Fertilidade do Solo do RS e SC, a aplicação de calcário é indicada para áreas de plantio direto consolidado quando o $\mathrm{pH}$ for menor que 5,5 e a saturação por bases da camada de $0-0,10 \mathrm{~m}$ for menor que $65 \%$ (CQFSRS/SC, 2004). Caso somente um desses critérios seja atendido, a aplicação só é indicada se a saturação por alumínio for superior a $10 \%$. Em uma situação de manejo uniforme (tradicional) da gleba, seriam os valores médios de $\mathrm{pH}$, saturação por bases e saturação por alumínio apresentados no quadro 1 os que seriam levados em consideração como critério para definir a necessidade de aplicação de calcário. Como o pH médio do solo foi de 5,5 (Quadro 1), a aplicação de calcário não seria indicada, apesar de estar no limite do valor crítico de $\mathrm{pH}$; porém seria indicada com base na saturação por bases, cujo valor médio foi de $55 \%$ (Quadro 1). Como somente um dos dois critérios foi atendido e a saturação por alumínio foi inferior a $10 \%$ (Quadro 1), a recomendação seria pela não aplicação de calcário na gleba.

Considerando, porém, uma situação de manejo localizado com base na agricultura de precisão, a aplicação de calcário seria recomendada em 40,6 \% da área (calcário calcítico mais dolomítico), levando em conta a espacialização gerada a partir dos critérios de $\mathrm{pH}$ menor que 5,5 e a saturação por bases menor que $65 \%$ (Figura $6 \mathrm{a}, \mathrm{b}$ ). A dose, com base em $1 / 2 \mathrm{SMP}$ (CQFSRS/SC, 2004), chegaria até a faixa de 1,76$2,20 \mathrm{Mg}$ ha $^{-1}$ para o calcário calcítico (Figura 6a) e de 0,86-1,75 $\mathrm{Mg} \mathrm{ha}^{-1}$ para o calcário dolomítico (Figura 6b). Isso representa, portanto, uma situação distinta daquela de manejo uniforme, em que não se recomendaria a aplicação de calcário. Possivelmente essa aplicação localizada de calcário aumentaria a produtividade das culturas nessas porções da gleba e, por conseguinte, na gleba como um todo. Resultados 
(a)

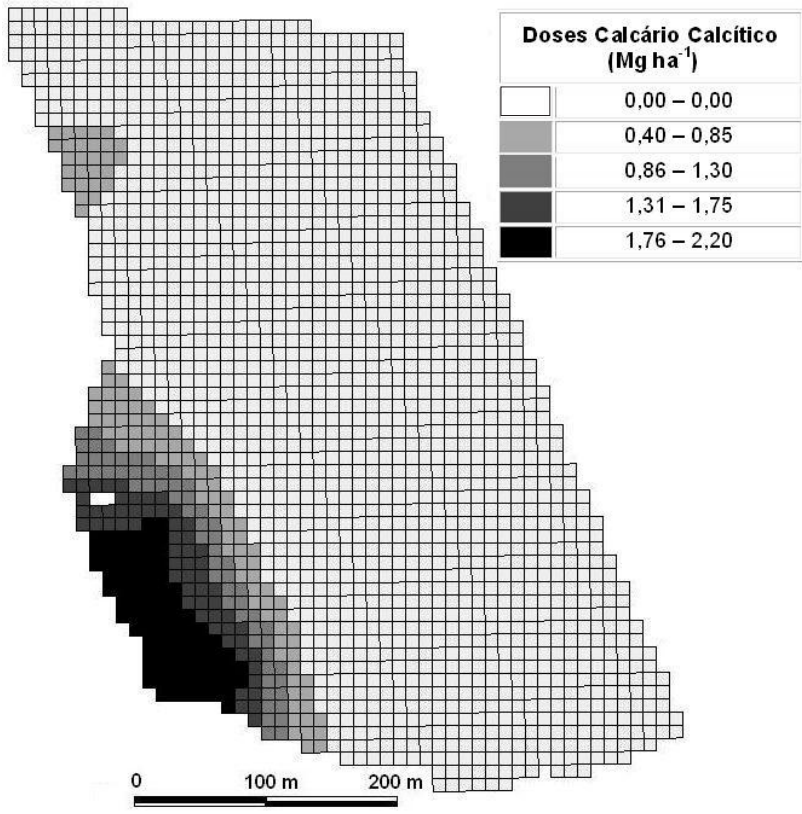

(b)

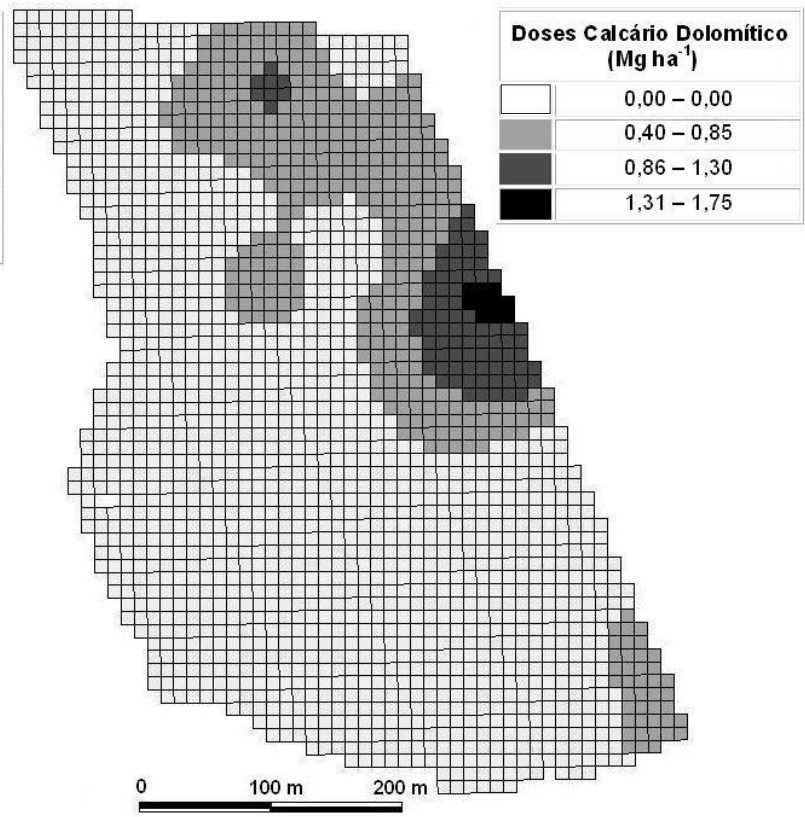

Figura 6. Espacialização de recomendação de aplicação de calcário: (a) calcítico e (b) dolomítico.

e conclusões semelhantes foram obtidos por Hurtado et al. (2009) após constatarem que no manejo uniforme a dose média de calcário a ser aplicada em uma gleba de Latossolo Vermelho cultivada com milho seria de $0,58 \mathrm{Mg} \mathrm{ha}^{-1}$, ao passo que no manejo localizado com agricultura de precisão as doses chegavam até a faixa de 1,5-2,0 Mg ha-1 em uma significativa porção da gleba. Todas essas constatações reforçam, portanto, as possibilidades de se obterem vantagens técnicas e econômicas com o emprego do manejo localizado em agricultura de precisão.

Além do manejo da dose de calcário, o emprego da agricultura de precisão nessa gleba possibilitaria também o manejo do elemento $\mathrm{Mg}$ no sentido de aumentar a saturação Mg:CTC e a relação Mg:K, identificados como críticos na árvore de regressão (Figura 3). Nesse caso, a estratégia seria adotar um plano de aplicação de duas fontes de calcário: calcítico e dolomítico. Em uma simulação dessa estratégia, adotou-se o teor de $\mathrm{Mg}$ no solo como critério para a definição da fonte de calcário, considerando-se os níveis propostos por CQFSRS/SC (2004): (a) calcítico, quando o teor de Mg no solo fosse alto (> 1,0 $\left.\mathrm{cmol}_{\mathrm{c}} \mathrm{L}^{-1}\right)$, e (b) dolomítico, quando o teor fosse médio ou baixo $\left(\leq 1,0 \mathrm{cmol}_{\mathrm{c}} \mathrm{L}^{-1}\right)$. Com base nessas indicações, $40 \%$ da porção a ser calcariada receberia calcário calcítico (Figura 6a), como usualmente o produtor vem fazendo na área nos últimos anos, e o restante da porção receberia calcário dolomítico (Figura 6b). Integralizando-se as necessidades de calcário com base em manejo localizado e considerando o valor médio para faixa de dose, o consumo total de calcário na gleba seria de 6,64 $\mathrm{Mg} \mathrm{ha}^{-1}$, sendo 3,20 $\mathrm{Mg} \mathrm{ha}^{-1}$ de dolomítico e 3,44 Mg ha-1 de calcítico, considerando-se um PRNT de $100 \%$. Essa abordagem de aplicação de tipos distintos de calcário em distintas porções da gleba já havia sido sugerida no trabalho de Hurtado et al. (2009), destacando assim outra vantagem proporcionada pela agricultura de precisão em termos de otimização de uso de insumos.

Com relação à adubação fosfatada e potássica para a cultura do milho, em um plano de manejo uniforme baseado na média dos teores de P-Mehlich (11,1 $\left.\mathrm{mg} \mathrm{dm}^{-3}\right) \mathrm{e} \mathrm{K}^{+}$(168 mg dm $\mathrm{m}^{-3}$ ) (Quadro 1), classificados respectivamente nos níveis alto e muito alto (CQFSRS/SC, 2004), a recomendação seria de $45 \mathrm{~kg} \mathrm{ha}^{-1}$ de $\mathrm{P}_{2} \mathrm{O}_{5}$ e $0 \mathrm{~kg} \mathrm{ha}{ }^{-1}$ de $\mathrm{K}_{2} \mathrm{O}$ (CQFSRS/SC, 2004). O consumo total de $\mathrm{P}_{2} \mathrm{O}_{5}$ seria, portanto, de $810 \mathrm{~kg}$ e o de $\mathrm{K}_{2} \mathrm{O}$ seria nulo.

No entanto, existe variabilidade nos teores de PMehlich na gleba (Figura 2a). A maior parte da área (70,0 \%) possui nível alto de $\mathrm{P}$ (de 6,1 a $12 \mathrm{mg} \mathrm{dm}^{-3}$ ) (Figura 2a), em conformidade com o observado anteriormente para manejo uniforme e requerendo, portanto, uma dose de $45 \mathrm{~kg} \mathrm{ha}^{-1} \mathrm{de}_{2} \mathrm{O}_{5}$ (Figura 7). Outra parte significativa $(29,4 \%)$ possui nível muito alto (> $12 \mathrm{mg} \mathrm{dm}^{-3}$ ) (Figura 2a), dispensando a adubação fosfatada. O restante da área (0,6 \%) possui níveis médios de $\mathrm{P}\left(4,1-6,0 \mathrm{mg} \mathrm{dm}^{-3}\right)$, requerendo adubação de $75 \mathrm{~kg} \mathrm{ha}{ }^{-1}$ de $\mathrm{P}_{2} \mathrm{O}_{5}$ (Figura 7). O consumo total de $\mathrm{P}_{2} \mathrm{O}_{5}$ na área seria, portanto, de $575 \mathrm{~kg}$, ou seja, aproximadamente 29 \% de redução no consumo desse fertilizante fosfatado em relação ao manejo uniforme. Esses resultados concordam com a 
afirmação de Amado et al. (2009), de que o teor médio de $\mathrm{P}$ do solo de uma gleba como critério de definição da dose do fertilizante fosfatado pode não ser o mais adequado, por conduzir a erros localizados.

No que se refere à adubação potássica, a diferença entre manejo uniforme e manejo localizado não seria tão expressiva quanto para a adubação fosfatada, o que é coerente com o fato de o K não ter sido identificado nas análises estatísticas (correlação de Spearman, árvore de regressão e análise de cluster) como um elemento crítico para manejo. A maior parte da gleba (75,0 \%) possui nível muito alto de $\mathrm{K}\left(>120 \mathrm{mg} \mathrm{dm}^{-3}\right.$, dado não apresentado), sem necessidade de adubação (Figura 8), o que contribuiria, aliado à aplicação de calcário dolomítico, para aumento da relação $\mathrm{Mg:K}$, identificado como um atributo crítico pela árvore de regressão (Figura 3). Contudo, algumas porções dentro da gleba (25,0 \%) possuem níveis altos de $\mathrm{K}$ (61-120 mg dm ${ }^{-3}$, dado não apresentado) e, nesse caso, a aplicação de $30 \mathrm{~kg} \mathrm{ha}^{-1}$ de $\mathrm{K}_{2} \mathrm{O}$ seria indicada (Figura 8), totalizando um consumo de $135 \mathrm{~kg}$ de $\mathrm{K}_{2} \mathrm{O}$ na gleba, contra um consumo nulo na estratégia de manejo uniforme.

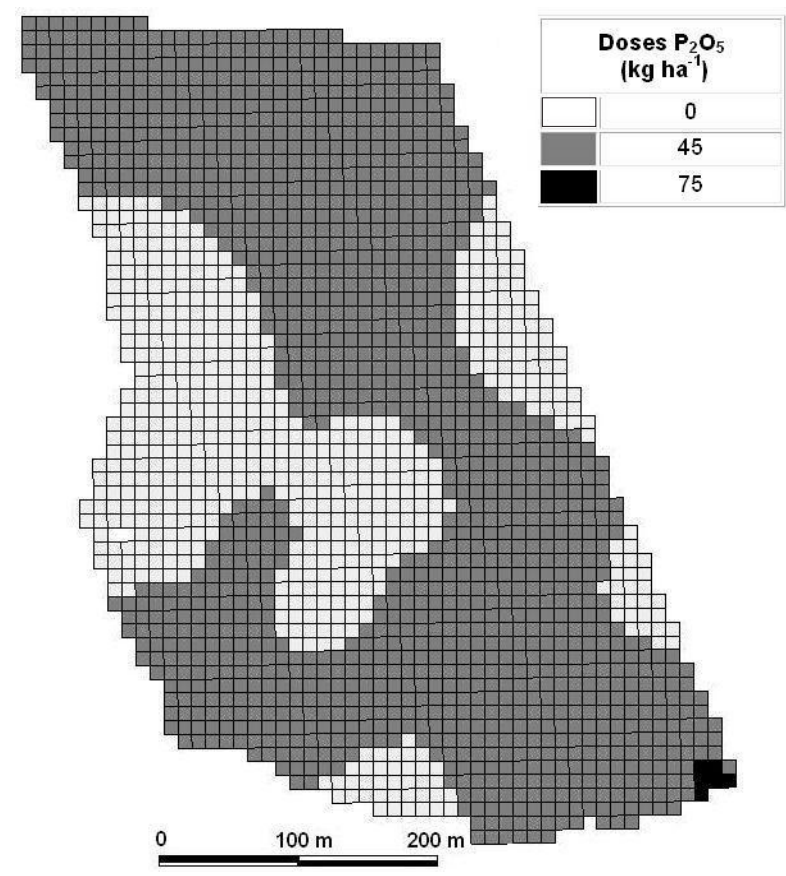

Figura 7. Espacialização de recomendação de adubação fosfatada.

Em um comparativo geral, o manejo localizado apresentaria maior consumo de calcário $(+6,64 \mathrm{Mg})$, menor de $\mathrm{P}_{2} \mathrm{O}_{5}(-235 \mathrm{~kg})$ e maior de $\mathrm{K}_{2} \mathrm{O}(+135 \mathrm{~kg})$ em relação ao manejo uniforme, porém aplicados ou suprimidos em partes específicas da área, o que é em última análise o princípio de otimização de uso de insumos proporcionado pela agricultura de precisão.

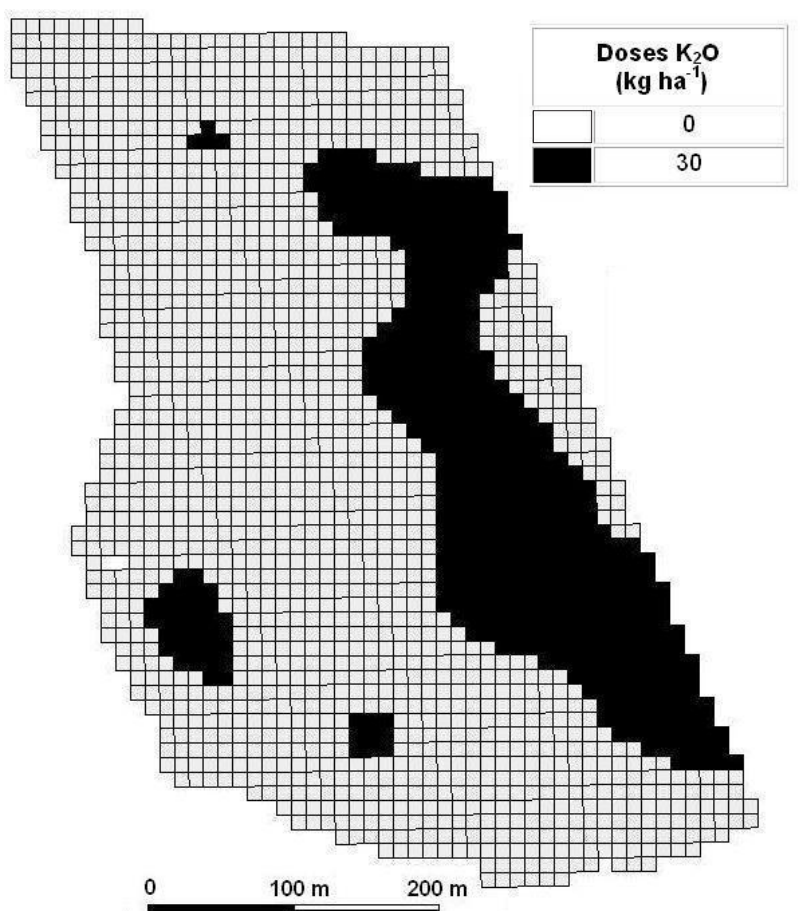

Figura 8. Espacialização de recomendação de adubação potássica.

\section{CONCLUSÕES}

1. As análises estatísticas de correlação de Spearman, árvore de regressão e análise de cluster foram adequadas para avaliar a importância de atributos de solo sobre a variabilidade espacial do rendimento de grãos de milho. Essa avaliação de importância de atributos subsidia a tomada de decisão sobre quais estratégias de manejo devem ser adotadas, sendo, no caso específico do estudo, as práticas de calagem e adubação fosfatada.

2. O emprego da agricultura de precisão é viável tecnicamente, quando baseada em tomadas de decisão com fundamentação estatística, no manejo prático de atributos de solo mesmo em áreas comerciais de milho com elevado potencial de rendimento, como ocorre na região de Guarapuava, Paraná. Além disso, possibilita utilização mais racional dos insumos, contribuindo para a otimização do rendimento aliado à promoção de qualidade ambiental.

\section{AGRADECIMENTOS}

À família do sr. Josef Stutz, pela cessão da gleba e de equipamentos, e à equipe técnica da MasseyFerguson AGCO, pelo suporte técnico dado na utilização dos equipamentos empregados no projeto. À LD Tecnologias Agrícolas, pelo apoio prestado na utilização do software SST-toolbox, e ao sr. Antonio Marcos Peterlini, pelos valorosos trabalhos realizados 
no campo. Ao SIMEPAR, pelas informações meteorológicas do local de estudo. Ao CNPq, pela concessão da bolsa PQ (J. Dieckow e A.C.V. Motta).

\section{LITERATURA CITADA}

AMADO, T.J.C.; PES, L.Z.; LEMAINSKI, C.L. \& SCHENATO, R.B. Atributos químicos e físicos de Latossolos e sua relação com rendimentos de milho e feijão irrigados. R. Bras. Ci. Solo, 33:831-843, 2009.

ARGENTA, G.; SILVA, P.R.F.; BORTOLINI, C.G.; FORSTHOFER, E.L. \& STRIEDER, M.L. Relação da leitura do clorofilômetro com os teores de clorofila extraível e de nitrogênio na folha de milho. R. Bras. Fisiol. Veg., 13:158-167, 2001.

BUCHLEITER, G.W. \& BRODAHL, M.K. Analysis of precision farming data with classification trees. In: INTERNATIONAL CONFERENCE ON PRECISION AGRICULTURE, 5., Bloomington, 2000. Proceedings... Bloomington, 2000. CD ROM.

BÜLL, L.T. Nutrição mineral do milho. In: BÜLL, L.T. \& CANTARELLA, H., eds. Cultura do Milho: Fatores que afetam a produtividade. Piracicaba, Potafós, 1993. p.62-145.

CAVIGLIONE, J.H.; KIIHL, L.R.B.; CARAMORI, P.H. \& OLIVEIRA, D. Cartas climáticas do Paraná. Londrina, Iapar, 2000. CD ROM.

COMISSÃO DE QUÍMICA E FERTILIDADE DO SOLO CQFSRS/SC. Manual de adubação e calagem para os Estados do Rio Grande do Sul e Santa Catarina. 4.ed. Porto Alegre, 2004. 400p.

COMPANHIA NACIONAL DE ABASTECIMENTO - CONAB. Série histórica de produtividade - Brasil. Disponível em http://www.conab.gov.br/conabweb/index.php?PAG=131. Acesso em 25 Maio 2010.

CORÁ, J.E.; ARAUJO, A.V.; PEREIRA, G.T. \& BERALDO, J.M.G. Variabilidade espacial de atributos do solo para adoção do sistema de agricultura de precisão na cultura da cana-de-açúcar. R. Bras. Ci. Solo, 28:1013-1021, 2004.

EMPRESA BRASILEIRA DE PESQUISA AGROPECUÁRIA EMBRAPA. Centro Nacional de Pesquisa de Solos. Sistema brasileiro de classificação de solos. Brasília, 1999. 412p.

FANCELLI, L.A. \& DOURADO NETO, D. Fisiologia da produção e aspectos básicos de manejo para alto rendimento. In: SANDINI, I.E. \& FANCELLI, L.A., eds. Milho: Estratégias de manejo para a região Sul. Guarapuava, Fundação Agrária de Pesquisa Agropecuária, 2000. p.103-116.

HERNANDEZ, R.J.M. \& SILVEIRA, R.I. Efeitos da saturação por bases, relações Ca:Mg no solo e níveis de fósforo sobre a produção de material seco e nutrição mineral do milho (Zea mays L.). Sci. Agric., 55:79-85, 1998.

HURTADO, S.M.C.; SILVA, C.A.; RESENDE, A.V.; von PINHO, R.G.; INÁCIO, E.S.B. \& HIGASHIKAWA, F.S. Spatial variability of soil acidity attributes and the spatialization of liming requirement for corn. Ci. Agrotec., $33: 1351-1359,2009$
KOPITTKE, P.M. \& MENZIES, N.W. A review of the use of the basic cation saturation ratio and the "ideal" soil. Soil Sci. Soc. Am. J., 71:259-265, 2007.

MARSCHNER, H. Mineral nutrition of higher plants. London, Academic Press, 1997. 674p.

MOLIN, J.P. Tendências da agricultura de precisão no Brasil. In: CONGRESSO BRASILEIRO DE AGRICULTURA DE PRECISÃO, Piracicaba, 2004. Anais... Piracicaba, ESALQ/ USP, 2004. CD ROM.

PAVAN, M.A.; BLOCH, M.F.; ZEMPULSKI, H.C.; MIYAZAWA, M. \& ZOCOLER, D.C. Manual de análise química de solo e controle de qualidade. Londrina, Iapar, 1992. 40p.

PIERCE, F.J. \& NOWAK, P. Aspects of precision agriculture. Adv. Agron., 67:1-85, 1999.

ROLOFF, G. \& FOCHT, D. Mapeamento dos atributos do solo: Malha ou zona de manejo? In: SIMPÓSIO SOBRE AGRICULTURA DE PRECISÃO, 3., Piracicaba, 2001. Relação de trabalhos. Piracicaba, ESALQ/USP, 2001. CD ROM.

ROLOFF, G.; FOCHT, D. \& SCHIEBELBEIN, L.M. Mining regional spatial field data for cause and effect relations involving soybeans yield. In: INTERNATIONAL CONFERENCE ON PRECICION AGRICULTURE, 8., St. Paul, 1998. Proceedings... St. Paul, American Society of Agronomy, Crop Science Society of America e Soil Science Society of America, 2006. CD ROM.

ROSA-FILHO, G.; CARVALHO, M.P.; ANDREOTTI, M.; MONTANARI, R.; BINOTTI, F.F.S. \& GIOIA, M.T. Variabilidade da produtividade da soja em função de atributos físicos de um Latossolo Vermelho distroférrico sob plantio direto. R. Bras. Ci. Solo, 33:283-293, 2009.

SCHIEBELBEIN, L.M. Atributos do solo espacializados e seu controle sobre a produtividade da soja em um Latossolo Vermelho distroférrico. Curitiba, Universidade Federal do Paraná, 2006. 73p. (Tese de Mestrado)

SCHIEBELBEIN, L.M.; ROLOFF, G. \& FOCHT, D. Diferentes formas de preparação e utilização dos dados oriundos de monitores de produtividade na análise da dependência espacial e correlação com variáveis do solo. In: CONGRESSO BRASILEIRO DE AGRICULTURA DE PRECISÃO, 2., São Pedro, 2006. Anais... Piracicaba, ESALQ/USP, 2006. CD ROM.

PARANÁ. Secretaria de Estado da Agricultura e Abastecimento do Paraná / Departamento de Economia Rural. SEAB/ DERAL. Área e produção agrícola no Estado do Paraná por unidade administrativa da SEAB: Tabelas de grãos de verão. Disponível em http://www.seab.pr.gov.br/modules/ conteudo/conteudo.php? conteudo=137. Acesso em 25 Maio 2010.

SILVA, V.R.; REICHERT, J.M.; STORCK, L. \& FEIJÓ, S. Variabilidade espacial das características químicas do solo e produtividade de milho em um Argissolo VermelhoAmarelo distrófico arênico. R. Bras. Ci. Solo, 27:10131020, 2003. 